\title{
Environmental and multi reinforcing effects of micro and nano fibers on adhesion properties of slow setting epoxy adhesives
}

\author{
J. R. Lee ${ }^{1}$, B. S. Kim ${ }^{2}$, B. K. Park ${ }^{1}$, D. H. $\mathrm{Oh}^{3}$ \& S. N. Lee ${ }^{1}$ \\ ${ }^{1}$ Advanced Materials Division, \\ Korea Research Institute of Chemical Technology, Korea \\ ${ }^{2}$ Composites Materials Lab, Korea Institute of Materials Research, Korea \\ ${ }^{3}$ Ahae Co. Ltd, Korea
}

\begin{abstract}
The chopped PVA fibers and vapor grown carbon nano tube (VGCNF) were used in reinforcing a room temperature curable epoxy resin system. This epoxy based nano-composite adhesive was used to attach Sus 316 steel plates. We have prepared the samples in spring and summer to check the environmental effects on the adhesion properties. The maximum contents of PVA fiber and VGCNF were 1.39 and $0.61 \%$, respectively. The samples have been preserved for two months at the laboratory to experience real environmental change. The mean temperature and moisture were $22^{\circ} \mathrm{C}$ and Relative Humidity of $52 \%$ for dry spring weather and $32^{\circ} \mathrm{C}$ and Relative Humidity of $85 \%$ for summer weather with monsoon. The addition of VGCNF was always helpful to increase the adhesion strength with the studied concentrations. The measured highest increase of adhesion strength was 1.84 times in the specimens with $0.61 \mathrm{wt} \%$ of VGCNF prepared in spring. The reinforcing effect by PVA fiber addition was dramatically changed by the concentration and seasonal environment. The maximum reinforcing effect on adhesion strength has been obtained with $0.35 \mathrm{wt} \%$ of PVA fiber. The increasing ratio of the strength was 3.01 times. But with the higher concentration of PVA fiber caused a very sharp decrease of adhesion strength. The combination effect of these two reinforcing materials is useful in low addition concentration, $0.35 \mathrm{wt} \%$, of PVA fiber also with the low addition concentrations, 0.15 and $0.3 \mathrm{wt} \%$, of VGCNF.
\end{abstract}

Keywords: VGCNF, PVA fiber, environmental, multi reinforcing, nano. 


\section{Introduction}

Epoxy resins are one of the most important thermosetting polymers and have wide applications in various industries especially in coatings and adhesives. Depending on the chemical structure of the base epoxy resins and hardeners, it is possible to vary physical properties, such as toughness, chemical resistance, and mechanical properties, ranging from extreme flexibility to high strength, high adhesion ability, good heat resistance, and high electrical resistance $[1,2]$. In nuclear application, epoxy resins are largely used to coat a large area of atomic power plant, more than 26 sections. In an atomic plant only slow setting at room temperature epoxy resins can be used. There are so many limitations for the adaptation of new epoxy resin system, because of quite a long term test and well accumulated approved data at various and in some cases in very severe conditions [3-6].

The nano-materials especially nano-carbon fibers or carbon nano-tube possesses admirable properties, low weight, high fracture toughness with a relatively high strength [7-10]. There are so many results to utilize these materials to reinforce epoxy resins in adhesion purposes such as matrix resins in carbon fiber reinforced plastics for aerospace application or in electronic applications. But there are few results to utilize on the utilization of these materials for slow setting epoxy resin systems in terms of environmental effects [11-22]. And further, there are nearly no results which deal with the effect of environmental problems for the room temperature curable slow setting composite adhesives in a practical aspect.

Especially in an atomic power plant slow setting epoxy resins are painted on a steel plate in a large area. The painting or adhesion is done every time throughout long term construction period during several years, in some bad cases in summer or in winter. The designed service life of an atomic power plant has been increased from 40 years to 60 years. Eventually the prediction of the properties change due to the environmental differences and the utilization of the new reliable materials should be accelerated. There will be a sharp increase of the number of atomic power plants worldwide over the next 2 or 3 decades. This new boom of long service life huge construction eventually requires new reliable material systems for better reliability. Also many high rise buildings and big ship buildings were accomplished during the last ten years worldwide. There would be another boom for high rise building which represent the worldwide economic growth for the next decades. But the strong earthquakes more frequently occurred in China, Chile, Japan, Indonesia, Haiti etc. In some cases they have accompanied very strong Tsunamis.

To avoid fatal destruction of structure and consequent damages, the structural reinforcing method should be developed using newly developed high performance materials. All such kinds of applications require a slow setting, in other words, cold curing, epoxy resin based adhesives with much improved strength. Also, for the real application, economically available materials should be considered. So we have decided to study the seasonal change effect on a room temperature curable slow setting epoxy system which has been reinforced by 
vapor grown carbon nano fiber (VGCF) and Poly Vinyl Alcohol (PVA) fiber at the same time. They have contradictory surface properties, hydrophobic and hydrophilic. VGCF is not very expensive and PVA fiber is currently applied in cement reinforcing purposes. They can be easily supplied and applied in practice even for on-going projects such as the emergency reinforcing of old bridges, dams, breakwater and buildings in a short period.

\section{Experimental}

\subsection{Materials}

The Sus 316 steel plates of $2 \mathrm{~mm}$ thickness were cut to have a dimension of $70 \mathrm{~mm} \times 20 \mathrm{~mm}$. The adhesion length has been controlled to $20 \mathrm{~mm}$ equal to the width of specimen, as the surface area of $4 \mathrm{~cm}^{2}$. After cutting the specimens adhesion surface of steel plate has been scratched by using sand paper \#600 to promote the retaining of the epoxy resins on the surfaces. The adhesion surface of the specimens was cleaned using acetone before applying the epoxy resin based adhesives. The two components cold curable epoxy resins produced by Ahae Co. Ltd were used to bond these Sus 316 steel plates. The base resin is Bisphenol type resin which has the epoxy equivalent of 210 and the viscosity of $2000 \mathrm{cps}$. The cyclo-aliphatic amine adduct type hardener has been used. The viscosity of hardener was $400 \mathrm{cps}$. The recommended formulating ratio between base resin and hardener was 2.3: 1 by weight. The used Kuralon PVA fiber from Kuraray co. has the cut length of $8 \mathrm{~mm}$, tensile strength of $1,300 \mathrm{MPa}$, dry Young's modulus of 320(cN/dtex), thickness of $15.0($ dtex $)$, dry elongation at break of $6.5 \%$, specific gravity of 1.3 . The graphite nanofiber GNF-100 from Carbon nano-materials technology co. has the diameter of 50-200nm, length of 10-30 micrometer, aspect ratio of more than 100, purity of more than $90 \mathrm{wt} \%$, bulk density of $0.18-0.20 \mathrm{~g} / \mathrm{cm}^{3}$.

\subsection{Test sample preparation and measurement}

Because of the inherent viscosity the VGCNF has been mixed with hardener and PVA fiber has been mixed with base resin to obtain a well dispersed mixture.

Each sample has been separately mixed by using planetary centrifugal mixer ARE-310.

The VGCNF containing hardener and PVA containing base resin have been mixed in a recommended ratio by using small mechanical stirrer in Teflon. The mixing ratio of $\mathrm{VGCNF}$ was $0.15,0.3,0.45$, and $0.61 \mathrm{wt} \%$. The mixing ratio of PVA fiber was $0.35,0.7$ and $1.39 \mathrm{wt} \%$. The maximum loading of filler was limited to $2 \mathrm{wt} \%$ in total. The formulated resins were applied on the adhesion surfaces to make lap shear strength test samples. The slight dead weight was applied on the specimens by Iron strip to assure contact and to maintain the adhesive levels between Sus 316 steel plates. Several precautions have been taken to maintain the evenness in thickness of adhesive film. The final thickness of adhesive film was in the range of $0.2 \mathrm{~mm}$. The samples have been prepared 
two times, in spring and in summer. In Korea, spring has a very dry weather and summer has hot-wet monsoon weather. More than two months passed to assure full cure for this slow room temperature setting epoxy resin system which was approved for use in construction. The mean temperature and moisture were $22^{\circ} \mathrm{C}$ and the relative humidity of $52 \%$ for dry spring weather and $32^{\circ} \mathrm{C}$ and relative humidity of $85 \%$ for summer monsoon weather. For every testing condition, five specimens have been prepared. The mechanical tests have been performed by using universal testing machine, Instron 5882 with the cross head speed of $10 \mathrm{~mm} / \mathrm{min}$.

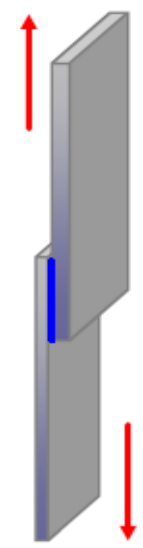

Figure 1: Illustration of sample test; structural adhesive shear and tensile strength tests.

\section{Results and discussion}

There are so many articles and books which adopt the misleading concept of cold curing for epoxy resin adhesives. This misleading concept of cold curing is very frequently found in many articles which deal with the results concerning environmental effects. The word "cold" is very vague. In practice, one cannot exactly define the cold curing conditions. It has been used as an opposite term to general heat curable epoxy resin systems. Heat curable epoxy resin systems can be classified to be cured at a medium temperature of about $100-150^{\circ} \mathrm{C}$ as a medium temperature curable system, and at high temperature of about 160$190^{\circ} \mathrm{C}$ as a high temperature curable system. And there are room temperature curing systems which can be cured at room temperature. For this room temperature curing system the advancement of the chemical reaction of cure is slow. Below $10-12^{\circ} \mathrm{C}$, the advancement of chemical reaction can be arrested. So, in general cold weather below $10^{\circ} \mathrm{C}$, the epoxy adhesives cannot perform their role as an adhesive. If one really want to cure epoxy resins below $10^{\circ} \mathrm{C}$ it would be possible to use a very reactive reaction catalyst or highly active hardener. But it will cause so many problems in real large scale application in construction. Because of the misleading cold curing concept there would be so many problems in applications of epoxy resin adhesives at a relatively low temperature outdoor 
environment. The epoxy resin adhesive systems which cure in room temperature should be influenced by so many environmental effects on their final properties, especially by temperature and moisture. In a real construction site we have observed that the relatively well cured state of the epoxy adhesives in very thin painting application of atomic power plant requires more than one month probably about two months [23-25]. During such a long period there would be many factors influencing the final properties. And further, the final conversion ratio of epoxy resin should be much differentiated by the seasonal environment conditions.

The epoxy resin adhesives without special toughening agents have a tendency to show brittle fracture. The incorporation of various fillers in epoxy resins can alter this inherent nature of epoxy resins. The moisture absorbing capability of the fillers should have a strong change on the curing behavior and final properties of construction application slow setting epoxy resins. So we have chosen two kinds of reinforcing fillers which have the contradictory surface properties, hydrophobic and hydrophilic, VGCNG and PVA fiber.

In Korea the humidity is lowest in spring time and highest in summer time. In winter, as we have mentioned earlier, it would be very difficult to get well cured epoxy resin adhesive samples. So we have decided to make our samples, in two terms during spring time and summer time at Daejeon in the central part of Korea. The results of the incorporation effect of VGCNF in spring and summer are shown in figures 2 and 3. In figure 2, the addition of the VGCNF sharply increased the adhesion strength and failure strain at the same time. The highest strength and failure strain was obtained with the highest concentration of VGCNF, $0.61 \mathrm{wt} \%$. The mechanical response of the adhesives was converted to be more tough and strong from very brittle and weak in spring season results. The summer season results were very different from spring season results as shown in figure 3 . The highest strain was obtained with the lowest concentration of VGCNF, $0.15 \mathrm{wt} \%$. The adhesive containing with $0.15 \mathrm{wt} \%$ VGCNF gave

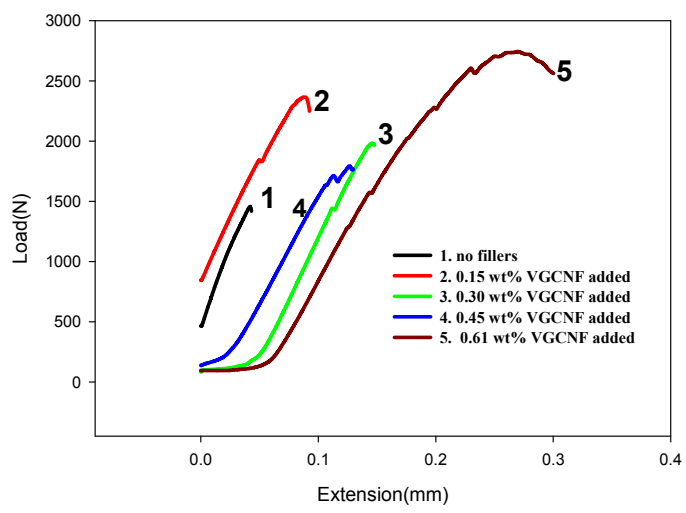

Figure 2: Concentration effect of VGCNF on the mechanical behavior of composite adhesive I in spring. 


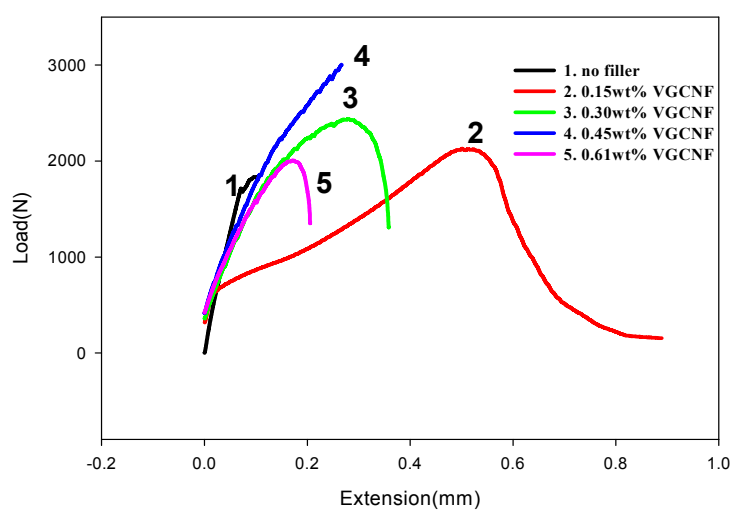

Figure 3: Concentration effect of VGCNF on the mechanical behavior of composite adhesive I in summer.

the highest adhesion strength. This fact shows that there is a very strong interaction between mechanical properties of a composite adhesive and the curing conditions where the environmental effect becomes one of the key factors.

The addition of nano fibers in brittle epoxy resin system eventually creates so much interfacial area. The role of such large area interface can be altered by the seasonal change which accompanies the change of curing temperature and moisture uptake change. This fact indicates that the interpretation of the nanofiber addition effect in epoxy resin systems requires so many precautions.

Finally, the excess amount of moisture which has been accumulated at the interface between VFCNF and epoxy resins seems to give a plasticizing effect. The absorbed moisture in this epoxy resin also plays an important role. The adhesion strength of the specimens prepared in summer is 1.25 times of that prepared in spring. The measured results of adhesion strength change by the addition of VGCNF were summarized in table 1. In every case the addition of VGCNF increased the adhesion strength.

Table 1: Addition and seasonal effect of change VGCNG on the strength change.

\begin{tabular}{|c|c|c|c|c|c|}
\hline \multirow{2}{*}{ Season } & \multicolumn{5}{|c|}{ Sample (Wt\%) } \\
\cline { 2 - 6 } & 0 & 0.15 & 0.3 & 0.45 & 0.61 \\
\hline Spring & 3.66 & 5.28 & 4.63 & 4.71 & 6.7 \\
$(\mathrm{MPa})$ & \pm 0.02 & \pm 0.62 & \pm 1.29 & \pm 0.93 & \pm 0.09 \\
\hline Summer & 4.56 & 5.96 & 6.23 & 8.14 & 5.30 \\
$(\mathrm{MPa})$ & \pm 0.45 & \pm 1.39 & \pm 0.65 & \pm 2.69 & \pm 0.39 \\
\hline
\end{tabular}




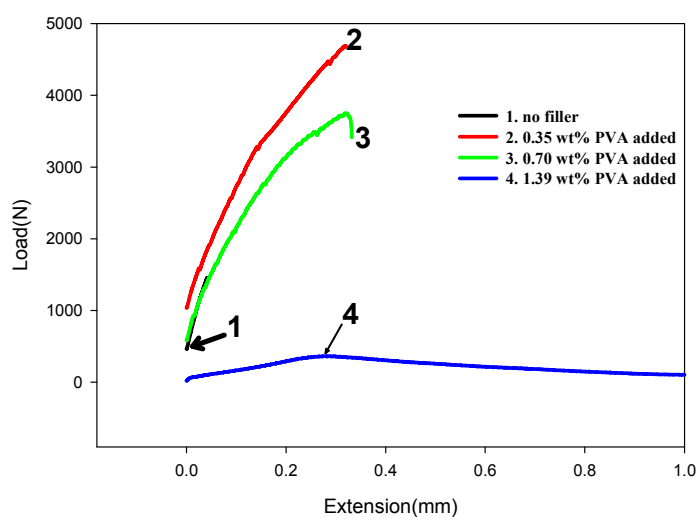

Figure 4: Concentration effect of PVA fiber on mechanical behavior of composite adhesive II in spring.

The maximum increase of adhesion strength was 1.84 times with $0.61 \mathrm{wt} \%$ in spring and 1.79 times with $0.45 \mathrm{wt} \%$ in summer. The highest adhesion value of $8.14 \mathrm{MPa}$ was observed in the specimens with the addition of $0.45 \mathrm{wt} \%$ of VGCNF in summer.

The incorporation effect of PVA fiber in spring and summer is presented in figures 4 and 5. The maximum load bearing capacity of the PVA fiber added adhesive has been much increased, about 3.01 times with $0.35 \mathrm{wt} \%$, and 2.56 times with $0.7 \mathrm{wt} \%$ in spring specimens as represented in figure 4 . But the load bearing capacity of the PVA fiber added adhesive has been sharply decreased to 0.19 times with $1.39 \mathrm{wt} \%$. This fact indicates that the control of the interface surface area is very important for the reinforcing effect of this material. The mechanical behavior of the specimens with the incorporation of PVA fiber prepared in summer is totally different from that prepared in spring, as shown in figure 5 .

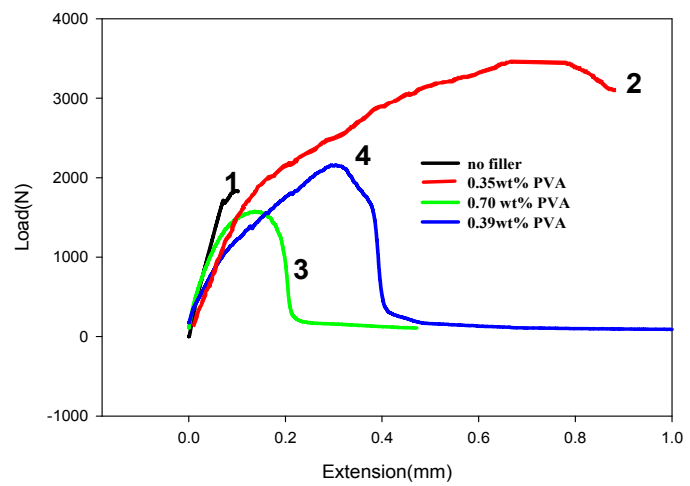

Figure 5: Concentration effect of PVA fiber on the mechanical behavior of composite adhesive II in summer. 
The moisture plasticized interface seems to give ductility to the mechanical behavior of the specimens. It has resulted in much extended failure strain.

The results of adhesion strength change by the addition of PVA fiber are given in table 2 .

Table 2: Addition and seasonal effect of change PVA fiber on the strength change.

\begin{tabular}{|c|c|c|c|c|}
\hline \multirow{2}{*}{ Season } & \multicolumn{4}{|c|}{ Sample(Wt\%) } \\
\cline { 2 - 5 } & 0 & 0.35 & 0.70 & 1.39 \\
\hline \multirow{2}{*}{ Spring(MPa) } & 3.66 & 11.03 & 9.36 & 0.68 \\
& \pm 0.02 & \pm 0.70 & \pm 0.84 & \pm 0.26 \\
\hline Summer & 4.56 & 8.50 & 3.945 & 4.83 \\
$(\mathrm{MPa})$ & \pm 0.45 & \pm 0.55 & \pm 0.6 & \pm 0.79 \\
\hline
\end{tabular}

The reinforcing effect of PVA fiber seems to be better than VGCNF in low concentration. The maximum increase of adhesion strength was 3.01 times with $0.35 \mathrm{wt} \%$ in spring and 1.86 times with $0.35 \mathrm{wt} \%$ in summer. The highest adhesion value of $11.03 \mathrm{MPa}$ was observed in the specimens with the addition of $0.35 \mathrm{wt} \%$ of PVA fiber in spring. The new attempt to search the combination effects of VGCNG and PVA fiber would encounter so many difficulties originated by the complexity of real phenomena. To avoid confusion, the compositions of various composite adhesives are represented in table 3.

Table 3: $\quad$ Compositions of the composite adhesives.

\begin{tabular}{|c|c|c|c|c|c|}
\hline I & II & III & IV & V & IV \\
\hline Epoxy & Epoxy & Epoxy & Epoxy & Epoxy & Epoxy \\
Resin & Resin & Resin & Resin & Resin & Resin \\
+ & + & + & + & + & + \\
VGCNF & PVA fiber & $0.15 w t \%$ & $0.3 \mathrm{wt} \%$ & $0.45 \mathrm{wt} \%$ & $0.61 \mathrm{wt} \%$ \\
only & only & VGCNF & VGCNF & VGCNF & VGCNF \\
& & + & + & + & + \\
& & PVA fiber & PVA fiber & PVA fiber & PVA fiber \\
\hline
\end{tabular}

The combination reinforcing effects of VGCNT and PVA fiber and the seasonal effects on the mechanical behavior of these composite adhesives are illustrated in figures 6-13. To minimize the complexity, the addition wt $\%$ of VGCNF has been fixed for every figure. And then the mechanical behavior change due to various concentrations of PVA fiber is presented. In figures 6 and 7 , the fixed concentration of VGCNF was $0.15 \mathrm{wt} \%$. One can find that the only 


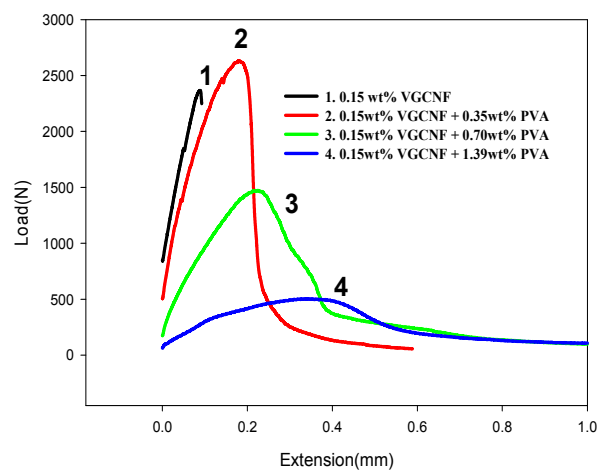

Figure 6: Concentration effect of VGCNF and PVA fiber on the mechanical behavior of composite adhesive III in spring.

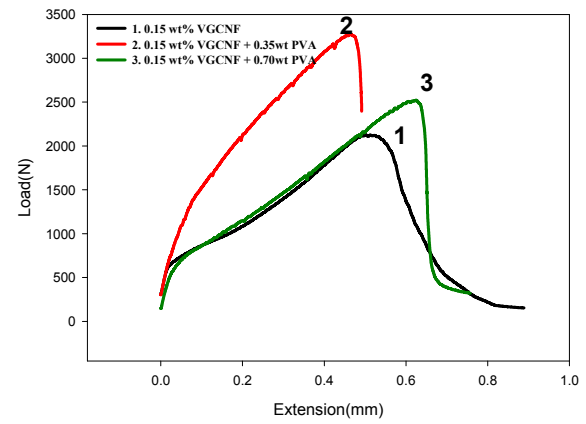

Figure 7: Combination effect of VGCNF and PVA fiber on the mechanical behavior of composite adhesive III in summer.

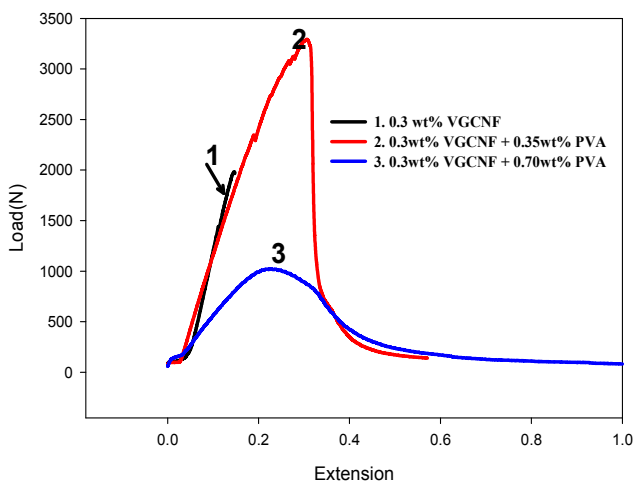

Figure 8: Combination effect of VGCNF and PVA fiber on the mechanical behavior of composite adhesive IV in spring. 
the very low addition, $0.35 \mathrm{wt} \%$, of PVA fiber is helpful to improve the adhesion strength with specimens prepared in spring The mechanical behavior of adhesives in the specimens prepared in summer is very different from that of the specimens prepared in spring. And the case with the high addition concentration, $1.39 \mathrm{wt} \%$, of PVA fiber was very difficult to get properly adhered specimens. So these specimens were omitted in the test. Anyhow, the strength increasing ratio is more improved in the specimens prepared in summer.

In figures 8 and 9 the fixed concentration of VGCNF was $0.30 \mathrm{wt} \%$. In figure 8 one can find that the addition of low concentration, $0.35 \mathrm{wt} \%$, of PVA fiber was very effective in increasing the adhesion strength. But the slight increase of the concentration of PVA fiber was very harmful. Also, in the case with the high addition concentration, $1.39 \mathrm{wt} \%$, of PVA fiber had been very difficult to get properly adhered specimens. So these specimens were omitted in the test. The results in figure 9 showed that the addition of any concentration of PVA fiber was useless in improving the adhesion strength. The specimens prepared in the summer showed a very complicated behavior. And the highly added PVA fiber gave regaining of the strength. This fact indicates that the excess moisture absorption is not helpful in improving the adhesion strength. Perhaps there is a limit to the optimum moisture concentration for each composite system. It will require very difficult and complex experiments over a long time to reveal these phenomena.

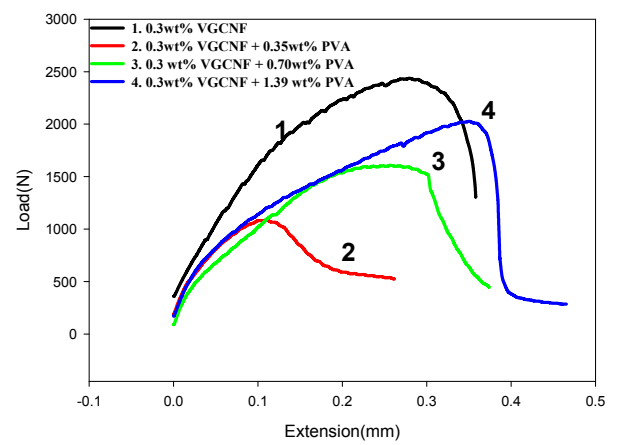

Figure 9: Combination effect of VGCNF and PVA fiber on mechanical behavior of composite adhesive IV in summer.

The combination effects of the two reinforcing materials with the fixed concentration of VGCNF of $0.45 \mathrm{wt} \%$ are presented in figures 10 and 11 . In these cases the addition of PVA fiber was not helpful in increasing the adhesion strength of these composite adhesives. It seems that there is an optimum condition to increase the adhesion strength. The occupied volume of reinforcing materials, its shape, moisture up-taking property and especially the surface properties are critical to the final crosslinking network structure of slow setting epoxy resin composites and final properties. 


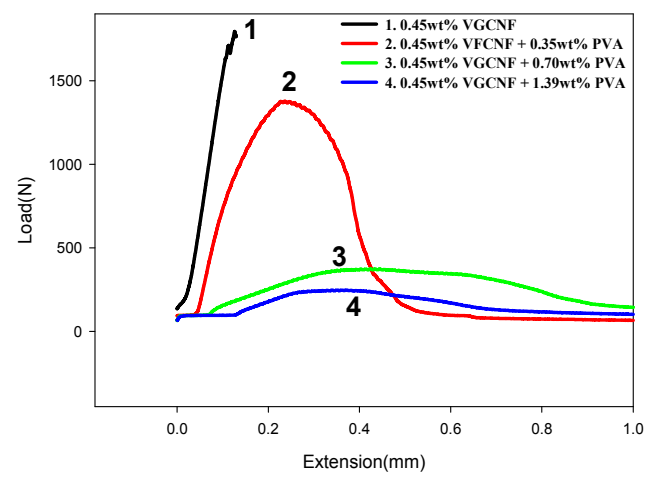

Figure 10: Combination effect of VGCNF and PVA fiber on the mechanical behavior of composite adhesive $\mathrm{V}$ in spring.

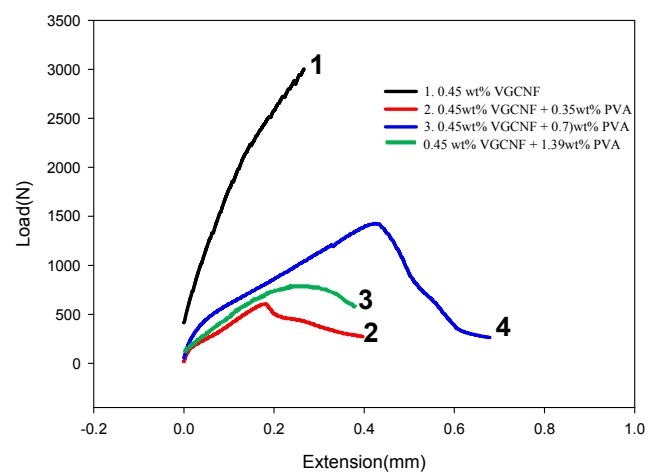

Figure 11: Combination effect of VGCNF and PVA fiber on the mechanical behavior of composite adhesive $\mathrm{V}$ in summer.

The results with the fixed concentration of VGCNF of $0.61 \mathrm{wt} \%$ are given in figure 12 and 13. In this case it was very difficult to get properly adhered specimens with the high addition concentration, $1.39 \mathrm{wt} \%$, of PVA fiber for two seasons. So these specimens were discarded before the test. As the results with the fixed concentration of VGCNF of $0.45 \mathrm{wt} \%$ shown in figure 10 and 11 , the addition of PVA fiber has no effect in improving the adhesion strength of these composite adhesives. The addition effect of PVA fiber in the specimens prepared in summer is a little more pronounced than those prepared in spring. This fact seems to indicate also that the moisture uptake and the fiber surface properties have a significant role in the final mechanical behavior.

This work should be extended to more large scale experiments. And then one can get more practical and important data for the reinforcing effects of these new materials in worldwide construction use. 


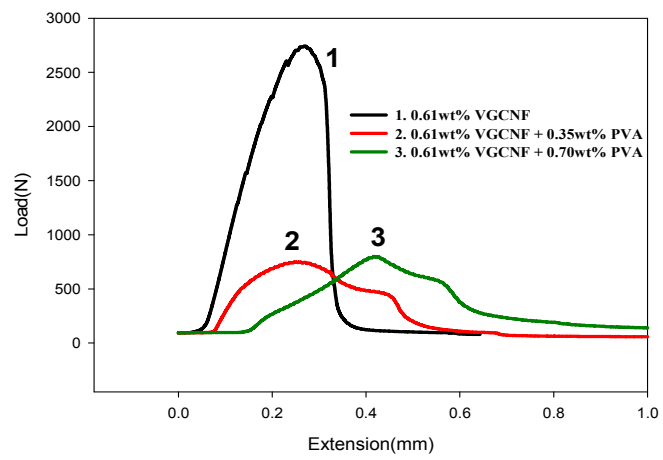

Figure 12: Combination effect of VGCNF and PVA fiber on the mechanical behavior of composite adhesive VI in spring.

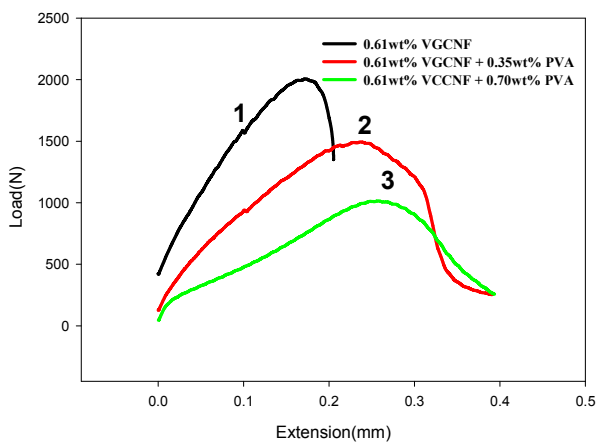

Figure 13: Combination effect of VGCNF and PVA fiber on the mechanical behavior of composite adhesive VI in summer.

\section{Conclusions}

The reinforcing effect of VGCNF and PVA fiber on epoxy resin based adhesives was very strongly influenced by the added concentration, seasonal environmental change and combination of these two reinforcing materials. The reinforcing effect of VGCNF is more constant than that of PVA fiber. The addition of VGCNF was always helpful in increasing the adhesion strength with the studied concentrations. The measured highest increase of adhesion strength was 1.84 times in the specimens with $0.61 \mathrm{wt} \%$ of VGCNF prepared in spring. The reinforcing effect by PVA fiber addition was dramatically changed by the concentration and seasonal environment. The maximum reinforcing effect on adhesion strength has been obtained with $0.35 \mathrm{wt} \%$ of PVA fiber. The increasing ratio of the strength was 3.01 times. But with the higher concentration of PVA fiber caused a very sharp decrease of adhesion strength. The combination effect of these two reinforcing materials is useful in low addition concentration, $0.35 \mathrm{wt} \%$, of PVA fiber also with the low addition concentrations, 0.15 and 
$0.3 \mathrm{wt} \%$, of VGCNF. The seasonal environmental change and the surface properties of reinforcing materials plays an important role eventually with the concentration change to determine the final mechanical behavior of these composite adhesives due to the various final state of crosslinking networks in the epoxy resin and the large surfaced interface structure between the epoxy resin and reinforcing materials.

\section{References}

[1] Bauer, R. S., Epoxy resin Chemistry, American Chemical Society: Washington, DC, 1979.

[2] Lee, H., Neville, K., handbook of Epoxy Resins, Mc-Graw Hill, New York, 1967.

[3] Lee, J. R., Park S. J., Seo M. K., Baik Y. K., Lee S. K., Effects of irradiation and design basis accident conditions on thermal properties of epoxy coating system for nuclear power plant, Nuclear Engineering and Design, 236, pp. 931-937,2006.

[4] Clough, R. L., Polymer Durability, Degradation, Stabilization and Lifetime Prediction, American Chemical Society Washington, DC, 1996.

[5] Pachner, J., "Systematic ageing management process: a key element for long term safety, reliability and economy of nuclear power plant", SMirt15, Seoul Korea, pp. 15-20 August, 1999.

[6] Theofanous, T. G., An assessment of steam-explosion-induced containment failure Nuclear Science and Engineering, 97, pp. 259-326,1987.

[7] Nalwa H. S., Encyclopedia of Nanoscience and Nanotechnology, American Scientific Publishers, 2004.

[8] Ebbesen T. W., Carbon Nanotubes, CRC Press, New York, 1997.

[9] Gogottsi Y., Nanotubes and Nanofibers, CRC Press, 2006.

[10] Schmid G., Nanoparticles, Wiley-VCH, 2004. Meguid S. A., On the tensile and shear strength of nano-reinforced composite interfaces, Materials \& Design, 25, pp. 289-296,2004.

[11] Spanoudakis, J., Young R. J., Crack propagation in a glass particle-filled epoxy resin, J. Mat. Sci., 19, pp. 473-486, 1984.

[12] Park S. W., Kim B. C. and Lee D. G., Tensile strength of joints bonded with a nano-particle reinforced adhesives, J. of Adhesion Science and Technology, 23, pp. 95-113, 2009.

[13] Rabindra N. D., Frank D. E., Voya R. M., Nano-and micro-filled conducting adhesives for z-axis interconnections: New direction for highspeed, high density, organic microelectronics packaging, J. Circuit World, 34, pp. 3-12, 2008.

[14] Gilbert E. N., Hayes B. S. and Seferis J. C., Nano-alumina modified epoxy based film adhesives, Polymer Engineering and Science, 43, pp. 10962005, 2003.

[15] Xu L. R., Li L., Lukehart M., and Kuai H., Mechanical Characterization of nanofiber-reinforced composite Adhesives, J. of Nanoscience and Nanotechnology, 7, pp. 1-3, 2007. 
[16] Hasegawa Kiichi, Adhesives of advanced functions and use development. Adhesives for bonding nano-composite with additions of clay minerals, Engineering Materials, 51, pp. 52-55, 2003.

[17] Zhu J. B., Yang X. J., Cui Z. D., Zhu S. L. and Wei Q., Preparation and properties of nano-SiO2/Epoxy composites cured by Mannich amine, J. of Macromolecular Science, Part B, 45, pp. 811-820, 2006.

[18] Frigione M., Naddeo C. and Acerno D., Cold-curing epoxy resins. Aging and environmental effects - II. Mechanical properties, J. of Polymer Engineering, 21, pp. 349-367, 2001.

[19] Frigione M., Naddeo C. and Acerno D., Cold-curing epoxy resins. Aging and environmental effects - I. Thermal properties, J. of Polymer Engineering, 21, pp. 23-51,2001.

[20] Broughton W. R. and Mera R. D., Cyclic fatigue testing of adhesive joints environmental effects, NPL Report CMMT (A), 192, Sept. 1999.

[21] Boone M. J., Mechanical testing of epoxy adhesives for naval applications, B.S. Maine Maritime Academy, 1995.

[22] Towse A., Potter K., Wisnom M. R. and Adams R. D., Specimen size effects in the tensile failure strain of an epoxy adhesive, J. of material Science, 33, pp. 4307-4314, 1998.

[23] Lee J. R., Park S. J., Seo M.K., Baik Y. K. and Lee S. K., A study on physicochemical properties of epoxy coating system for nuclear power plants, Nuclear Engineering and Design, 236, pp. 931-937, 2006.

[24] Bauer, R. S., Epoxy resin Chemistry, American Chemical Society: Washington, DC, 1979.

[25] Lee J. H., Kim S. W., Park H. S., Kim D. K., Jung Y. J., Lee J. S., Lee J. R., Park S. J., Kwon H., Park W. B., A Deterioration Test and Valuation on the Non-Metallic Liner in natural Condition-Wolsung Nuclear Power Plants 2,3,4-, April 1998, Korea Electric Co, Korea Institute of Construction Technology and Korea Research Institute of Chemical Technology. 